\title{
Using potassium ferrate as advanced treatment for municipal wastewater
}

\author{
Hongbo Wanga,b,* Haining Li ${ }^{\mathrm{a}}$, Ning Ding ${ }^{\mathrm{a}}$, Mei Li ${ }^{\mathrm{a}}$, Ning Wang ${ }^{\mathrm{a}, *}$ \\ aSchool of Municipal and Environmental Engineering, Shandong Jianzhu University, Jinan 250101, Shandong, China, \\ email: wanghongbo@sdjzu.edu.cn (H.Wang),986272112@qq.com (H. Li), 1223478347@qq.com (N. Ding), \\ limei@sdjzu.edu.cn (M. Li), wangning@sdjzu.edu.cn (N. Wang) \\ ${ }^{b}$ Shandong Co-Innovation Center of Green Building, Jinan, China
}

Received 7 September 2017; Accepted 14 February 2018

\section{A B S T R A C T}

Potassium ferrate is a potential high efficient chemical for wastewater treatment as a combination of oxidant and flocculent. In this research, potassium ferrate was used to treat simulated wastewater and secondary effluent of a wastewater treatment and the removal performance was evaluated base on the treatment of chemical oxygen demand (COD), total organic carbon (TOC), suspended solid (SS) and total phosphorous (TP). The results present that the organic matters (indexed by COD and TOC) could be effectively eliminated during both the oxidation stage and flocculation stage while SS and TP were majorly got rid of during flocculation stage. The effects of $\mathrm{pH}$, reaction time and potassium ferrate dosing were also investigated and the optimum conditions were found as: The potassium ferrate concentration of $40 \mathrm{mg} / \mathrm{L}$, oxidation time of $20 \mathrm{~min}$ ( $\mathrm{pH}$ of 10.31), and flocculation time of $30 \mathrm{~min}$ ( $\mathrm{pH}$ of 3.28) except TP and SS removals; For secondary effluent, potassium ferrate of $40-50 \mathrm{mg} / \mathrm{L}, 25 \mathrm{~min}$ of oxidation, and $20 \mathrm{~min}$ of flocculation.

Keywords: Potassium ferrate; Municipal wastewater; Advanced treatment

${ }^{*}$ Corresponding author. 